\title{
A Procedure for Obtaining a Family of Iterative Formulas of Higher Order
}

\author{
Dragomir M. Simeunović
}

ABSTRACT. In this paper a procedure for obtaining iterative formulas of higher order for finding zeros is obtained. The family includes several already known results.

In this paper, starting from Halley's iterative formula (see [1], [2]) for finding zeros of the functions, a family of iterative formulas of the third order has been obtained.

Halley's iterative formula for finding the simple zero of the function $F(x)$ is

$$
x_{k+1}=x_{k}-\frac{2 F\left(x_{k}\right) F^{\prime}\left(x_{k}\right)}{2\left(F^{\prime}\left(x_{k}\right)\right)^{2}-F\left(x_{k}\right) F^{\prime \prime}\left(x_{k}\right)}, \quad k=0,1,2, \ldots,
$$

where $F(x)$ is three times differentiable function.

Formula (1) we can write in the form

$$
x_{k+1}=x_{k}-\frac{F\left(x_{k}\right)}{F^{\prime}\left(x_{k}\right)} \cdot \frac{1}{1-\frac{F\left(x_{k}\right) F^{\prime \prime}\left(x_{k}\right)}{2\left(F^{\prime}\left(x_{k}\right)\right)^{2}}}, \quad k=0,1,2, \ldots .
$$

Expression

$$
1-\frac{F\left(x_{k}\right) F^{\prime \prime}\left(x_{k}\right)}{2\left(F^{\prime}\left(x_{k}\right)\right)^{2}}
$$

can be written in the form

$$
1-\frac{F\left(x_{k}\right) F^{\prime \prime}\left(x_{k}\right)}{2\left(F^{\prime}\left(x_{k}\right)\right)^{2}}=1-s+s\left(1-\frac{F\left(x_{k}\right) F^{\prime \prime}\left(x_{k}\right)}{2 s\left(F^{\prime}\left(x_{k}\right)\right)^{2}}\right),
$$

where $s$ is a real parameter $\neq 0$.

As it is known, for small values $|h|$ of the real number $h$ and real parameter $v \neq 0$, the following relation is valid

$$
1-h \approx\left(1-\frac{h}{v}\right)^{v}
$$

2000 Mathematics Subject Classification. Primary: $65 \mathrm{H} 05$.

Key words and phrases. Iteration formulas, Approximate solutions of equations. 
If $x_{k}$ is an approximative value of the simple zero $\alpha$ of the function $F(x)$ that is near enough to the zero $\alpha$, then the value of $F\left(x_{k}\right)$ is small, and so the absolute value of the expression

$$
\frac{F\left(x_{k}\right) F^{\prime \prime}\left(x_{k}\right)}{2 s\left(F^{\prime}\left(x_{k}\right)\right)^{2}}
$$

is also small.

If we put expression (6) into (5) instead of $h$, we will get a relation

$$
1-\frac{F\left(x_{k}\right) F^{\prime \prime}\left(x_{k}\right)}{2 s\left(F^{\prime}\left(x_{k}\right)\right)^{2}} \approx\left(1-\frac{F\left(x_{k}\right) F^{\prime \prime}\left(x_{k}\right)}{2 s v\left(F^{\prime}\left(x_{k}\right)\right)^{2}}\right)^{v},
$$

because of which (4) is reduced to a relation

$$
1-\frac{F\left(x_{k}\right) F^{\prime \prime}\left(x_{k}\right)}{2\left(F^{\prime}\left(x_{k}\right)\right)^{2}} \approx 1-s+s\left(1-\frac{F\left(x_{k}\right) F^{\prime \prime}\left(x_{k}\right)}{2 s v\left(F^{\prime}\left(x_{k}\right)\right)^{2}}\right)^{v} .
$$

If in the formula (2) instead of expression (3) we put

$$
1-s+s\left(1-\frac{F\left(x_{k}\right) F^{\prime \prime}\left(x_{k}\right)}{2 s v\left(F^{\prime}\left(x_{k}\right)\right)^{2}}\right)^{v}
$$

we will get an iterative formula

(9) $x_{k+1}=x_{k}-\frac{F\left(x_{k}\right)}{F^{\prime}\left(x_{k}\right)} \cdot \frac{1}{1-s+s\left(1-\frac{F\left(x_{k}\right) F^{\prime \prime}\left(x_{k}\right)}{2 s v\left(F^{\prime}\left(x_{k}\right)\right)^{2}}\right)^{v}}, \quad k=0,1,2, \ldots$,

where $s$ and $v$ are real parameters $\neq 0$.

It is not difficult to prove for formula (9) that it represents an iterative formula of the third order.

By formula (9) it is given one family of iterative methods of the third order, where $s$ and $v$ are real parameters $\neq 0$.

The asymptotic error constant for the iterative method (9) is

$$
C_{3}=\frac{3\left(3+2(v-1)(2 s v)^{-1}-1\right)\left(F^{\prime \prime}(\alpha)\right)^{2}-4 F^{\prime}(\alpha) F^{\prime \prime \prime}(\alpha)}{24\left(F^{\prime}(\alpha)\right)^{2}},
$$

where $\alpha$ is a simple zero of the function $F(x)$.

Taking for parameters $s$ and $v$ different values, we can obtain from (9) particular iterative formulas. Here we list some of the particular cases:

1) For $s=1, v=1$, (9) reduces to Halley's method (2).

2) For $s=v=\frac{1}{2}$, we have from (9) Euler's method (see [1])

$$
x_{k+1}=x_{k}-\frac{F\left(x_{k}\right)}{F^{\prime}\left(x_{k}\right)} \cdot \frac{2}{1 \pm\left(1-\frac{2 F\left(x_{k}\right) F^{\prime \prime}\left(x_{k}\right)}{\left(F^{\prime}\left(x_{k}\right)\right)^{2}}\right)^{1 / 2}}, k=0,1,2, \ldots
$$


3) For $s=1, v=-1$, from (9) we obtain

$$
x_{k+1}=x_{k}-\frac{F\left(x_{k}\right)}{F^{\prime}\left(x_{k}\right)} \cdot \frac{2\left(F^{\prime}\left(x_{k}\right)\right)^{2}+F\left(x_{k}\right) F^{\prime \prime}\left(x_{k}\right)}{2\left(F^{\prime}\left(x_{k}\right)\right)^{2}}, \quad k=0,1,2, \ldots,
$$

which represents Chebyshev's method (see [7]).

4) For $s=\frac{n-1}{n}, v=\frac{1}{2}$, when $F(x)$ is a polynomial of degree $n \geq 2$, we have from $(9)$

$$
x_{k+1}=x_{k}-\frac{F\left(x_{k}\right)}{F^{\prime}\left(x_{k}\right)} \cdot \frac{n}{1 \pm(n-1)\left(1-\frac{n}{n-1} \cdot \frac{F\left(x_{k}\right) F^{\prime \prime}\left(x_{k}\right)}{\left(F^{\prime}\left(x_{k}\right)\right)^{2}}\right)^{1 / 2}}, k=0,1,2, \ldots,
$$

which is the Laguerre method (see [1], [3]).

5) For $s=1, v=\frac{1}{2},(9)$ reduces to

$$
x_{k+1}=x_{k}-\frac{F\left(x_{k}\right)}{F^{\prime}\left(x_{k}\right)} \cdot \frac{1}{ \pm\left(1-\frac{F\left(x_{k}\right) F^{\prime \prime}\left(x_{k}\right)}{\left(F^{\prime}\left(x_{k}\right)\right)^{2}}\right)^{1 / 2}}, \quad k=0,1,2, \ldots,
$$

which represents Ostrowski's square root method (see [4]).

6) For $s=\frac{1}{w+1}, v=\frac{1}{2}$, the formula (9) reduces to

$$
x_{k+1}=x_{k}-\frac{F\left(x_{k}\right)}{F^{\prime}\left(x_{k}\right)} \cdot \frac{w+1}{w \pm\left(1-(w+1) \cdot \frac{F\left(x_{k}\right) F^{\prime \prime}\left(x_{k}\right)}{\left(F^{\prime}\left(x_{k}\right)\right)^{2}}\right)^{1 / 2}}, k=0,1,2, \ldots,
$$

where $w$ is a real parameter $\neq-1$.

The family of iterative formulas (15) are obtained by E. Hansen and M. Patrick [1].

7) For $s=v=-1$, we have from (9) the formula

$$
x_{k+1}=x_{k}-\frac{F\left(x_{k}\right)}{F^{\prime}\left(x_{k}\right)} \cdot \frac{2\left(F^{\prime}\left(x_{k}\right)\right)^{2}-F\left(x_{k}\right) F^{\prime \prime}\left(x_{k}\right)}{2\left(F^{\prime}\left(x_{k}\right)\right)^{2}-2 F\left(x_{k}\right) F^{\prime \prime}\left(x_{k}\right)}, \quad k=0,1,2, \ldots,
$$

which is obtained in [5].

8) For $s=1, v=\frac{n-1}{2 n}$, when $F(x)$ is a polynomial of degree $n \geq 2$, we obtain from (9)

$$
x_{k+1}=x_{k}-\frac{F\left(x_{k}\right)}{F^{\prime}\left(x_{k}\right)} \cdot\left(1-\frac{n}{n-1} \cdot \frac{F\left(x_{k}\right) F^{\prime \prime}\left(x_{k}\right)}{\left(F^{\prime}\left(x_{k}\right)\right)^{2}}\right)^{\frac{1-n}{2 n}}, \quad k=0,1,2, \ldots,
$$

which represents the method obtained in [6].

The family of iterative method (9) is one particular case of one more general family of iterative methods obtained in [6]. 


\section{REFERENCES}

[1] E. Hansen, M. Patrick, A family of root finding methods, Numer. Math., 27 (1977), 257-269.

[2] M. Davies, B. Dawson, On the global convergence of Halley's iteration formula, Numer. Math., 24 (1975), 133-135.

[3] E.N. Laguerre, Oeuvres de Laguerre, Vol. 1, pp. 87-103.

[4] A.M. Ostrowski, Solution of Equations and Systems of Equations, Second edition, Academic Press, New York and London, 1966.

[5] D. M. Simeunović, On a process for obtaining iterative formulas of higher order for roots of equations, Anal. Num. Theor. Approx., 24 (1995), 225-229.

[6] D. M. Simeunović, A procedure for obtaining iterative formulas of higher order, Math. Moravica, Vol. 3 (1999), 67-75.

[7] И.С. Березин, Н.П. Житков, Методы вычислений, том II, Государственное издательство физико-математической литературы, Москва, 1960.

Dragomir M. Simeunović

Mike Alasa 8

11000 BELGRADE

Serbia 